\title{
Schwannomas of Peripheral Nerves: Unusual Cause of Sciatic and Literature Review
}

\section{Schwanomas dos nervos periféricos: causa rara de ciatalgia e revisão da literatura}

\author{
Juliano Nery Navarro ${ }^{1}$ Rodrigo de Almeida Simon Sola ${ }^{1}$ Telmo Augusto Barba Belsuzarri ${ }^{1}$ \\ Renata de Melo Braga Marques ${ }^{2}$ João Flávio Mattos Araujo ${ }^{3}$
}

\footnotetext{
${ }^{1}$ Medical Resident, Department of Neurosurgery, Hospital Celso Pierro PUC-Campinas, Campinas, SP, Brazil

2 Medical Pathologist Hospital Celso Pierro PUC-Campinas and CAISM/ UNICAMP, Universidade Estadual de Campinas, Campinas, São Paulo, Brazil

${ }^{3}$ Medical Neurosurgeon, Department of Neurosurgery, Hospital Celso Pierro PUC-Campinas, Campinas, SP, Brazil
}

\begin{abstract}
Address for correspondence Juliano Nery Navarro, MR, Department of Neurosurgery, Hospital Celso Pierro/PUC-Campinas, Rua Morgado de Mateus, $n^{\circ}$ 314, apt 31, São Paulo, SP, Brazil CEP: 04015-050 (e-mail: navarrojuliano@gmail.com).
\end{abstract}

Arq Bras Neurocir 2015;34:195-199.

\begin{abstract}
Schwannomas of peripheral nerves are the most common benign tumors in this location; it has specific radiologic and histologic features that enable its fundamental Keywords

- myelin sheath

- tumor

- peripheral

- schwannoma

- sciatic distinction of neurofibromas. Given its importance in neurosurgical practice, known radiologic and histologic criteria must be updated regarding this disease entity, as well as its therapeutic strategy and results obtained with it. This article reviews this subject, followed by a case report considered out of the ordinary, in which the tumor was located in the sciatic nerve in a patient with neurofibromatosis type 1 , treated by microsurgical resection, which evolved favorably.

Resumo

Palavras-chave

- bainha de mielina

- tumor

- periférico

- schwannoma

- isquiático

Os schwannomas dos nervos periféricos são os tumores benignos mais comuns nesta localização. Apresentam características radiológicas e histológicas específicas que possibilitam a sua fundamental distinção dos neurofibromas. Dada a sua importância na prática neurocirúrgica, devem ser conhecidos os critérios radiológicos e histológicos atualizados à respeito desta entidade nosológica, bem como sua estratégia terapêutica e o resultado com ela obtido. Neste artigo, é feita uma revisão do tema, seguido do relato de um caso considerado fora do habitual, no qual o tumor localizava-se no nervo ciático, em uma paciente portadora de neurofibromatose tipo 1, tratada por meio de ressecção microcirúrgica, que evoluiu de forma favorável.
\end{abstract}

\section{Introduction}

Schwannomas are the most common benign tumors of the peripheral nerves, but they represent less than $8 \%$ of all softtissue tumors. ${ }^{1-3}$ The incidence of benign schwannomas involving peripheral nerves tends to be higher in women than in men. ${ }^{1}$

received

November 24, 2014

accepted

June 12, 2015
DOI http://dx.doi.org/

10.1055/s-0035-1560033. ISSN 0103-5355.
Benign peripheral nerve schwannoma (BPNS) characteristically presents as a generally single, oval, eccentric, and painless mass present some time ago in a deep place in the course of a nerve or plexus element. ${ }^{1,2}$ However, this tumor can also be present as multiple lesions in patients with neurofibromatosis type 2 (NF2), Carney complex type 1 ,

Copyright $\odot 2015$ by Thieme Publicações License terms Ltda, Rio de Janeiro, Brazil

() (1) $\Theta \circledast$ 
and schwannomatose. ${ }^{1}$ It may occur in NF1 patients, but neurofibromas are much more common in this population. ${ }^{1,2}$

The segmental schwannomatose is characterized by multiple schwannomas located in a member without vestibular nerve tumors, more common in women aged 30 to 60 years; this condition could be a variant form of neurofibromatosis $(\mathrm{NF}){ }^{4-6}$

Malignant degeneration of BPNSs is rare, whereas the rate of malignant peripheral nerve sheath gets to be 18 times higher in patients with neurofibromatosis type 1 (NF1) and plexiform neurofibroma, and also radiation is a risk factor described. $^{7}$

Because the growth of schwannomas of peripheral nerves usually occurs over many years, large lesions slowly stretch and lengthen the fascicles. Thus, neurologic function tends to be intact in these tumors. ${ }^{1,2}$ Some neurologic deficit in smaller benign schwannomas is also rare, unless a biopsy has damaged the nerve involved or unsuccessful attempt has been made to remove the tumor with resultant nerve damage. Under these circumstances, the residual mass can be very painful, motor loss in the distribution of the involved nerve can be severe, and the sensitivity can be markedly reduced or absent. ${ }^{1}$

On palpation the tumor can be moved laterally but not longitudinally toward the tumor trajectory. ${ }^{1}$ The percussion on the mass can produce the Tinel sign, a warning sign more useful in diagnosis. ${ }^{2}$

The ultrasound was done previously for diagnostic investigation and can still be used to define the peripheral nerve tumors. With the advent of computed tomography (CT) and magnetic resonance imaging (MRI), however, soft tissue and nerve became more visible. The "gold standard" for imaging of peripheral nerve tumors became MRI. ${ }^{7-13}$ If a solitary palpable mass is clinically found in a patient and suspected as tumor of the peripheral nerve, a simple MRI of the extremity involved, or even a contrast, with fat suppression is advised. ${ }^{7}$

The radiologic features of schwannomas on MRI are homogeneous mass, with medium- to low-signal intensity on T1-weighted sequences, while presenting with T2 hyperintense sign ${ }^{2}$; after infusion of contrast, these tumors show great enhancement. ${ }^{1,9}$ Ancient schwannomas can produce different images, with areas of low-signal intensity due to the presence of hyaline degeneration and fibrosis. ${ }^{14-17}$ The "target sign" present in 50\% of cases is due to central hypo(fibrous component) and hyperintensity in the periphery (component myxedema). ${ }^{2}$

Schwannomas are often encapsulated, whereas neurofibromas are normally not; detection of the capsule that causes a rim of hypointense border of the tumor and the presence of the nerve along the side of the lesion help distinguish them from neurofibromas. ${ }^{10}$

If multiple palpable tumors, NF, or schwannomatose call for possibility of the clinical examination, the analysis should be more comprehensive, including several full column to set any spinal or foraminal mass. ${ }^{7}$

New techniques using magnetic resonance neurography have the potential to offer better visualization and definition of mass lesions of peripheral nerve, and produce images with higher-resolution nerves with greater separation of the adjacent soft tissue. $^{7}$

Schwannomas are benign tumors arising in the Schwann cells, with important and specific histopathologic features. ${ }^{1,2}$ Macroscopic appearance is characteristic in the form of wellcircumscribed mass with degenerative changes and variable mixture spindle compact area (Antoni A) and microcystic hypocellular area (Antoni B) rich in macrophages and collagen fibers. A collagenous capsule thus formed is a consistent finding and the hyalinized vessels. ${ }^{18}$ At immunohistochemical analysis schwannomas typically show strong diffuse expression of S100 protein and abundant pericellular collagen IV, consistent with the presence of a continuous pericellular blade basal. Glial fibrillary acidic protein (GFAP) is expressed in a subset of schwannomas. ${ }^{18}$

Recent positive markers in schwannomas often include podoplanin, calretinin, and SOX10. ${ }^{19,20}$ Typical schwannomas may very rarely show aberrant expression of cytokeratin. $^{19,20}$

Unlike neurofibromas, the neurofilament protein staining is restricted to axons normally trapped in the periphery of the tumor, although some recent studies suggest that the presence of intralesional axons is actually more frequent than previously described. ${ }^{18,19}$

The cellular schwannoma, although relatively rare, is an important variant of schwannoma. Because of its high cellularity, the fascicular pattern of growth, increased mitotic activity, and occasional locally destructive behavior, including bone erosion, it often appears malignancy. Cellular schwannoma is defined as a schwannoma composed almost entirely of one fascicle compact Schwann cell proliferation, with well-differentiated bland cytological without Verocay bodies. $^{18,21}$

Important clues to the diagnosis include the presence of foamy histiocytic aggregates, a well-formed capsule containing lymphoid aggregates and diffuse $\mathrm{S} 100$ protein and strong, and pericellular expression of collagen IV. ${ }^{18}$ Diffuse expression of S100 protein is extremely unusual in fusiform neural malignancies, and this finding should always raise the possibility of cellular schwannoma. Cytokeratin immunoreactivity can be seen in some cellular schwannomas, and it may represent cross-reactivity with GFAP. ${ }^{18,21}$

\section{Case Report}

A 47-year-old patient, diagnosed with NF1, was referred to the neurosurgery service at the Catholic University of Campinas due to the appearance of a lump in the left thigh high, gradually growing in size at the posterior region associated with pain for nearly 2 years. The pain was described as burning, constant, receiving score 8 in verbal numeric scale, started in the upper third of the thigh, and radiating the back of the limb to the lateral aspect of the foot.

Physical examination revealed dysesthesia-like burning in the territory of the right sciatic nerve without paresis and alterations in tendon reflexes, in tropism, or muscle tone. The root tests and the corticospinal tract were normal. MRI of the 


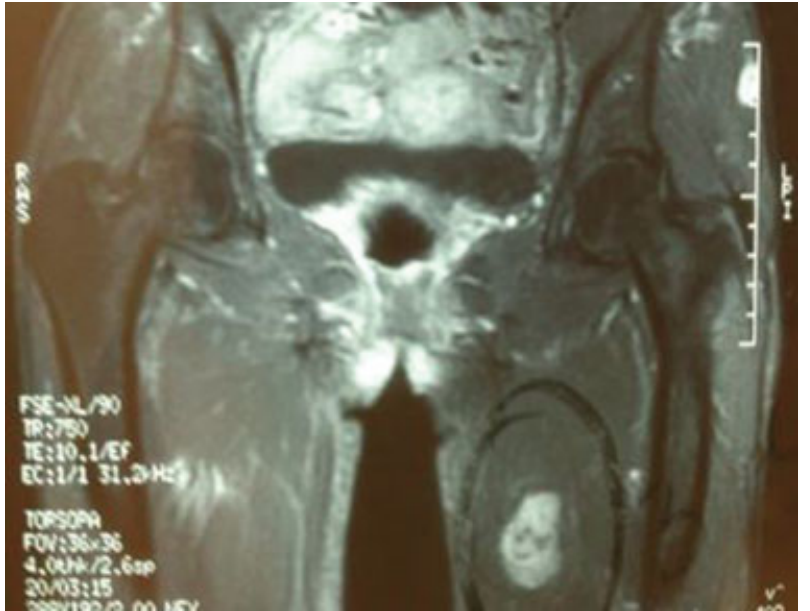

Fig. 1 T2-weighted MRI of the left thigh showing a regular, homogeneous, and hyperintense lesion, in the path of the sciatic nerve, with subtle hypointense margin on his capsule.

hip and thigh showed a regular, oval lesion adjacent to the left sciatic nerve, with hyperintensity on T2-weighted sequences, associated with a hypointense rim (-Fig. 1).

Days after the radiologic examination, the patient underwent surgery for resection of the lesion. The technique of microsurgical dissection was performed at the edges of the capsule, followed by lateralization and longitudinal incision at the tumor base, thereby providing the complete removal of the lesion after the separation of the issues related to the tumor (-Figs. 2 and 3). There was no fascicle section.

In the immediate postoperative period, the patient was asymptomatic, with no change in the neurologic examination, with complete reversal of neuropathic pain, graduating in pain verbal numeric scale to 0 , which remained in the following outpatient. The pathologic result was typical schwannoma (-Figs. 4 and $\mathbf{5}$ ).

\section{Discussion}

The treatment of BPNS is surgical, aiming for complete tumor resection using microsurgical technique., ${ }^{1,2,8,11-13}$ Serious

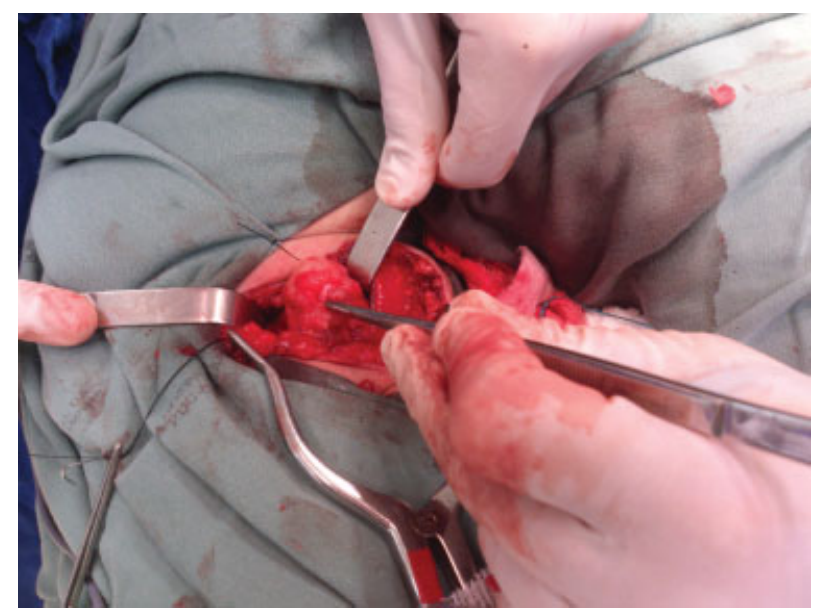

Fig. 2 Surgical exposure of the tumor in the upper third of the posterior left thigh using pericapsular dissection.

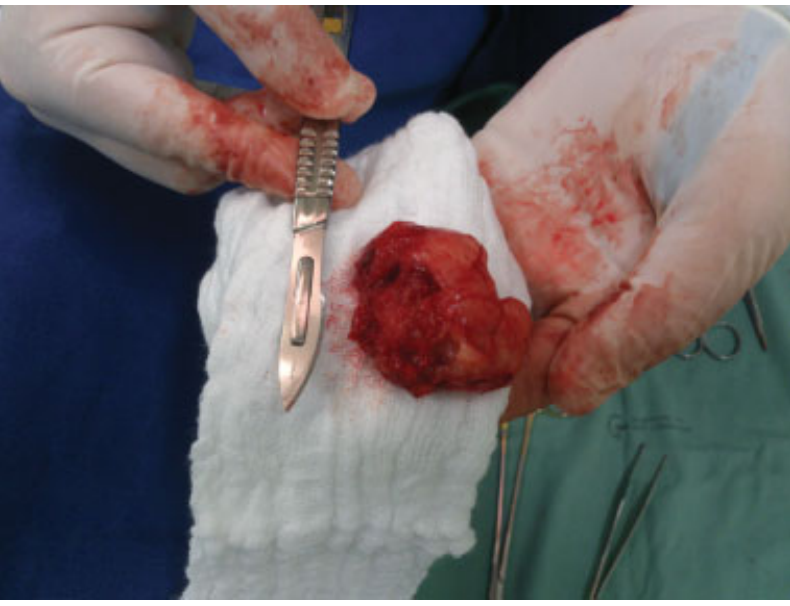

Fig. 3 Regular encapsulated lesion, approximately $4.5 \mathrm{~cm}$ in diameter in the anterior-posterior axis and $3 \mathrm{~cm}$ in lateral-lateral axis, showing section at its base to expose the adjacent nerve fascicles and enable complete resection.

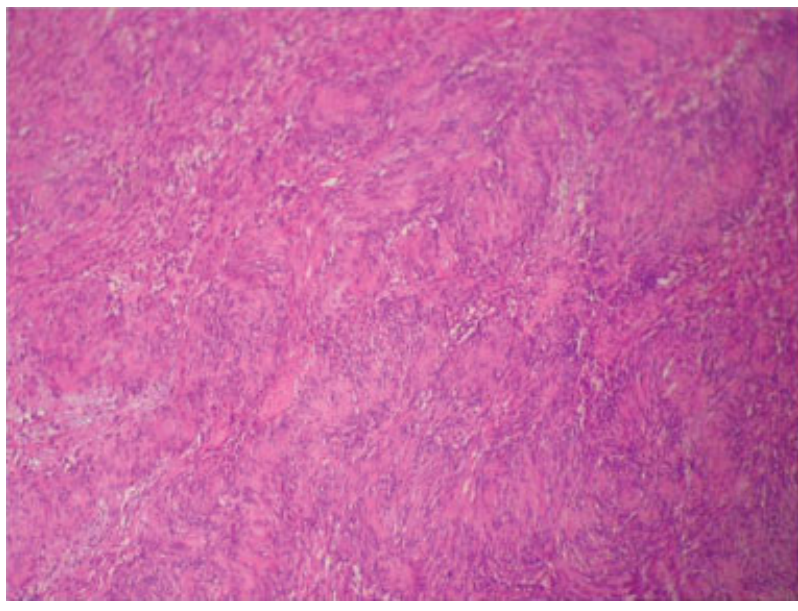

Fig. 4 Tumor composed of uniformly spindled Schwann cells with Antoni A (cellular fascicular) and Antoni B (myxoid; vacuolated) regions.

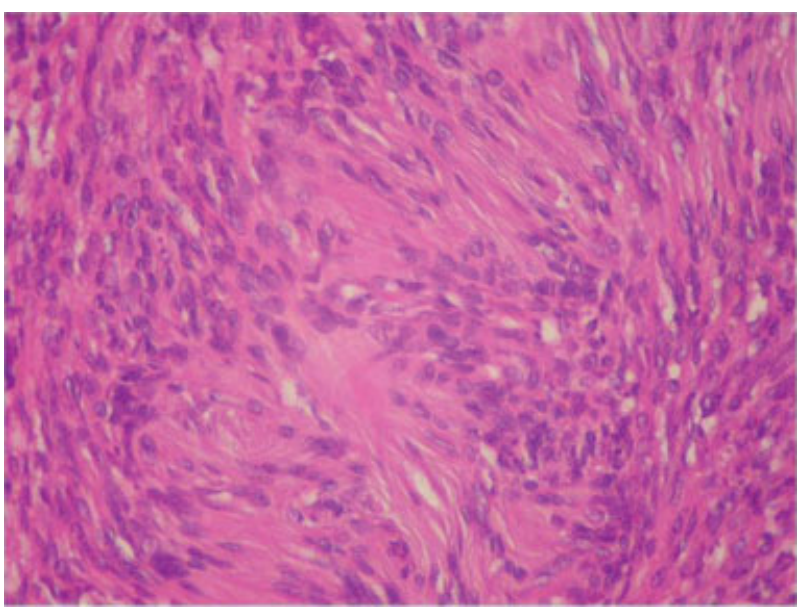

Fig. 5 Antoni A region with Verocay bodies (eosinophilic cores and nuclear palisading). 
complications can occur if care is not taken with dissection and preservation of elements of the plexus or nerves involved. ${ }^{1}$ Exposure of the nerve well proximal and distal to the lesion origin is required. ${ }^{1,2}$ Other elements of the plexus or nerves and vessels are dissected and spared. An area on the perimeter of the capsule with little or no specification is then opened longitudinally. ${ }^{1,2}$ The encapsulated tumors are separated from their fascicles, moving them toward the periphery. ${ }^{2}$ These fascicles can be adhered to the outer surface of the tumor capsule, although they are rarely built inside the capsule. $^{1}$

The capsule and the fascicles "basketed" are gently dissected and moved laterally to expose the tumor. ${ }^{1,2}$ The interfascicular dissection is then made in the proximal and distal poles of the tumor. ${ }^{1,2}$

Sometimes two small fascicles are seen entering and exiting the tumor, and these are exposed and surrounded by loops of vessels. ${ }^{1}$ Electric stimulation and acquisition through the booklets that come in and out of each pole are then performed if equipment is available. ${ }^{1}$ Stimulation of fascicles generally does not produce distal muscle function or perform the fascicles of neuronal action potential through the tumor to distal elements. ${ }^{1}$ These proximal or distal nonfunctional fascicles are sectioned, and the tumor is removed as a single mass. ${ }^{1}$ One way to do this is a section on entry or exit of nonfunctional issue, raising the tumor at that end and dissecting the underlying issues and keeping the most retained fascicles. ${ }^{1,2}$ The nonfunctional specification of the opposite end is then severed to complete the removal. $^{1}$

An alternative approach sometimes used in large tumors is to open the capsule along and enucleate the homogeneous or sometimes cystic tumor content, using suction, forceps and scissors, or a Cavitron ultrasonic surgical aspirator (CUSA). ${ }^{1,2}$ The fascicles are spared and scrutinized away from the tumor capsule, which is then resected. The capsule is completely removed to reduce the chance of recurrence, although some surgeons do not agree with this concept and leave it, believing that there can be less risk of injury to the involved nerve. $^{1,2}$

Some schwannomas become quite large and extend beyond the immediate region of the nerve. These lesions are more difficult to dry out, which increases the possibility of recurrence of the tumor remnants or capsule. ${ }^{1}$

In case of BPNS with malignant degeneration, treatment is based primarily on surgical excision with free margins. The radiotherapy provides local control and can delay the onset of recurrence, but has little effect on the long-term survival. Malignant tumors are those traditionally unresponsive to chemotherapy because most cases are soft-tissue sarcomas. $^{7,22}$

A subgroup of this type of spinal tumor deserves to be mentioned because of its proximity and specific topographic features. They are mostly solitary, sporadic, and originated entirely from the intradural dorsal root. ${ }^{23}$ Spinal schwannomas initially generate local pain and radicular symptoms often at a later stage. ${ }^{1,23}$ Classification of Asazuma and collaborators helps decide what type of surgery to be per- formed for spinal "halter" schwannomas in its approach resection, and recurrence after standard treatment with complete wide excision is rare (except in cases of NF2). ${ }^{23}$

In reviewing 30 years of experience in the treatment of tumors of the nerve sheath reported in Youmans Neurological Surgery, 6th ed, ${ }^{1}$ it was found that the schwannomas were less common than neurofibromas in brachial and pelvic plexus, and that most brachial plexus schwannomas were located in the supraclavicular region. The degrees of pre- and postoperative strengths were compared to determine the effectiveness of surgical treatment, with worsening in only 8 of 76 cases (10.5\%) surgically addressed. ${ }^{1}$

Adani et $\mathrm{al}^{2}$ reported in 2014 a series of 34 patients with schwannomas located in the upper limbs, treated with microsurgical technique by the technique of intracapsular enucleation. Immediate postoperative sensory deficit was identified in 28 patients ( $82 \%$ ), and only one deficit persisted 12 months after the procedure. There were no cases of paresis. Also, this series showed that the location of the tumor did not appear to be related to the final outcome, despite having been no lesion in brachial plexus. ${ }^{2}$

Schwannomas of the sciatic nerve (SSN) are rare, with a frequency lower than $1 \%{ }^{24-26}$ The posterior tibial nerve is most frequently involved in the lower limbs nerve. ${ }^{27}$ The most frequent clinical presentation of SSN consists of palpable painful mass. ${ }^{28-30}$

Eroglu et $\mathrm{al}^{27}$ recently published, in Turkish Neurosurgery, the case report of a 40-year-old patient who presented with schwannoma of the sciatic nerve in the posterior region of the right thigh and underwent complete resection of the lesion using the technique of enucleation of the capsule. The postoperative result described was great, without having any kind of pain or neurologic deficit. ${ }^{29}$

This case confirmed the clinical, radiologic, and histologic, features consistent with benign schwannoma of the sciatic nerve, and was also of great importance in the differential diagnosis with neurofibromas, especially in patients with NF1. It demonstrated the possibility of conducting technique initially preserving the capsule, allowing a complete resection of the lesion and a satisfactory outcome.

\section{Conclusion}

Patients who have chronic sciatica without radicular signs, history of low back pain, or radicular compression on imaging studies should have as one of the diagnostic hypotheses of schwannoma of the sciatic nerve.

The literature lacks reports about BPNSs in the lower limbs, including their surgical technique and surgical outcome.

More reports and comparative studies are needed to establish whether there is any specific feature in benign schwannomas of peripheral nerves in the upper limbs than the lower limbs, as well as the surgical technique used in their approach and the outcome after surgery. It is also necessary to elucidate whether factors such as duration of symptoms, the clinical presentation, and lesion size affect the therapeutic outcome. 


\section{References}

1 Friedman AH, Kline DG, Kim DH, Kitagawa RS. Benign tumors of the peripheral nerve. In: Youmans Neurological Surgery. 6th ed. Philadelphia, PA: Elsevier Saunders; 2011:2518-2521

2 Adani R, Tarallo L, Mugnai R, Colopi S. Schwannomas of the upper extremity: analysis of 34 cases. Acta Neurochir (Wien) 2014; 156(12):2325-2330

3 Carroll SL. Molecular mechanisms promoting the pathogenesis of Schwann cell neoplasms. Acta Neuropathol 2012;123(3):321-348

4 Wang ZX, Chen SL, Yi CJ, Li C, Rong YB, Tian GL. [Segmental schwannomatosis in upper-extremity: 5 cases report and literature review]. Beijing Da Xue Xue Bao 2013;45(5):698-703

5 Roth RR, Martines R, James WD. Segmental neurofibromatosis. Arch Dermatol 1987;123(7):917-920

6 Adigun CG, Stein J. Segmental neurofibromatosis [Review]. Dermatol Online J 2011;17(10):25

7 Gupta G, Mammis A, Maniker A. Malignant peripheral nerve sheath tumors. Neurosurg Clin N Am 2008;19(4):533-543, v

8 Adani R, Baccarani A, Guidi E, Tarallo L. Schwannomas of the upper extremity: diagnosis and treatment. Chir Organi Mov 2008; 92(2):85-88

9 Hems TEJ, Burge PD, Wilson DJ. The role of magnetic resonance imaging in the management of peripheral nerve tumours. J Hand Surg [Br] 1997;22(1):57-60

10 Ichikawa J, Sato E, Haro H, Anayama S, Ando T, Hamada Y. Posterior interosseous nerve palsy due to schwannoma: case report. J Hand Surg Am 2008;33(9):1525-1528

11 Kang HJ, Shin SJ, Kang ES. Schwannomas of the upper extremity. J Hand Surg [Br] 2000;25(6):604-607

12 Park MJ, Seo KN, Kang HJ. Neurological deficit after surgical enucleation of schwannomas of the upper limb. J Bone Joint Surg Br 2009;91(11):1482-1486

13 Sawada T, Sano M, Ogihara H, Omura T, Miura K, Nagano A. The relationship between pre-operative symptoms, operative findings and postoperative complications in schwannomas. J Hand Surg [Br] 2006;31(6):629-634

14 Isobe K, Shimizu T, Akahane T, Kato H. Imaging of ancient schwannoma. AJR Am J Roentgenol 2004;183(2):331-336

15 Vlychou M, Dailiana ZH. Ancient schwannoma of the hand. J Hand Surg Am 2011;36(12):2030-2033
16 Beaman FD, Kransdorf MJ, Menke DM. Schwannoma: radiologic-pathologic correlation. Radiographics 2004;24(5): $1477-1481$

17 Tanabe K, Tada K, Ninomiya H. Multiple schwannomas in the radial nerve. J Hand Surg [Br] 1997;22(5):664-666

18 Rodriguez FJ, Folpe AL, Giannini C, Perry A. Pathology of peripheral nerve sheath tumors: diagnostic overview and update on selected diagnostic problems. Acta Neuropathol 2012;123(3):295-319

19 Nascimento AF, Fletcher CD. The controversial nosology of benign nerve sheath tumors: neurofilament protein staining demonstrates intratumoral axons in many sporadic schwannomas. Am J Surg Pathol 2007;31(9):1363-1370

20 Naber U, Friedrich RE, Glatzel M, Mautner VF, Hagel C. Podoplanin and CD34 in peripheral nerve sheath tumours: focus on neurofibromatosis 1-associated atypical neurofibroma. J Neurooncol 2011;103(2):239-245

21 White W, Shiu MH, Rosenblum MK, Erlandson RA, Woodruff JM. Cellular schwannoma. A clinicopathologic study of 57 patients and 58 tumors. Cancer 1990;66(6):1266-1275

22 Perrin RG, Guha A. Malignant peripheral nerve sheath tumors. Neurosurg Clin N Am 2004;15(2):203-216

23 Greenberg MS. Manual de Neurocirurgia. 7th ed. Porto Alegre, Brazil: Artmed; 2010:822

24 Ghaly RF. A posterior tibial nerve neurilemoma unrecognized for 10 years: case report. Neurosurgery 2001;48(3):668-672

25 Hamdi MF, Aloui I, Ennouri Kh. Sciatica secondary to sciatic nerve schwannoma. Neurol India 2009;57(5):685-686

26 Kralick F, Koenigsberg R. Sciatica in a patient with unusual peripheral nerve sheath tumors. Surg Neurol 2006;66(6):634-637

27 Eroglu U, Bozkurt M, Ozates O, Akturk S, Tuna H. Sciatic nerve schwannoma: case report. Turk Neurosurg 2014;24(1):120-122

28 Omezzine SJ, Zaara B, Ben Ali M, Abid F, Sassi N, Hamza HA. A rare cause of non discal sciatica: schwannoma of the sciatic nerve. Orthop Traumatol Surg Res 2009;95(7):543-546

29 Rekha A, Ravi A. Sciatic nerve schwannoma. Int J Low Extrem Wounds 2004;3(3):165-167

30 Tan LA, Bradbury J, Bonnin J, Horn EM. Minimally invasive resection of an extrapelvic sciatic schwannoma. J Clin Neurosci 2010;17(10):1314-1316 